Military Technical College

Kobry El-Kobbah, Cairo, Egypt

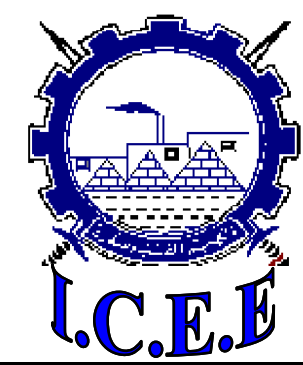

PT-2 $5^{\text {th }}$ International Conference on

Chemical \& Environmental

Engineering

25 - 27 May, 2010.

\title{
PHOTOCHROMIC BEHAVIOR OF SPIROPYRAN IN POLYURETHANE THIN FILMS
}

Ahmed A. Bhran ${ }^{*}$, Christian Fonteix ${ }^{*}$, Sandrine Hoppe ${ }^{*}$ and Anne Jonquiè ${ }^{* *}$

\begin{abstract}
The aim of this work is to characterize the photochromic properties of a commercial grade of polyurethane (PU) that contains small quantities of spiropyran (SP) [1-hexyle-3,3-dimethyl6'-nitrospiro (indoline-2',2'-benzopyran)]. PU photochromic films were illuminated with ultraviolet irradiation $(365 \mathrm{~nm})$ at room temperature and the absorbance spectra are recorded after scanning from 400 to $800 \mathrm{~nm}$ (visible zone). The effects of film thickness, irradiation time, and SP concentration on the polymer photochromic response have been studied. Furthermore, the photochromic behavior of polymer films under stretching and the kinetics of thermal decoloration of these films will be discussed.
\end{abstract}

\section{Keywords}

Photochromic Behavir, Spiropyran, Thermal Decoloration,Polyurethan Film

\footnotetext{
* Laboratoire des Sciences du Genie chimique, Nany Universite, France

${ }^{* *}$ Lanboratoire de Chimie-physique Macromoleculaire,Nany Universite, France
} 


\section{INTRODUCTION}

The photochromism of spiropyrans (SP) was first discovered by Fischer and Hirshberg [1] in 1952 and since then SP compounds have been extensively studied due to their practical application in many fields, in particular, for optical recording [2, 3], memories and switches [4, 5]. Photochromic SP exhibit changing of their color or more generally their absorbance spectra when irradiated with a source of light due to the formation of its merocyanine (MC) isomer [6]. The colored merocyanine returns spontaneously to SP in the dark or by irradiation in the spectral region of the induced absorbance as it is shown by the reversible reaction presented in figure 1 . The use of applicable polymers that are effective in protecting spiropyrans and provide stability against degradation without reducing their photochromic activity is a crucial factor. The photochromic behavior of spiropyrans in polymer films is of increasing interest despite the fact that their photocoloration rate decreases compared with that of liquid solutions, after the dispersion into the polymer matrix. Also, the number of cycles in which the photochromic systems undergo a reversible transformation is limited because of photodegradation processes [7-10].

These polymeric effects are most strongly pronounced when the SP are bound chemically to the polymer; they are indeed related with the reduction of chain segment mobility. The polymer matrix rigidity may influence the different deactivation process involved in these photochemical reactions, but it affects strongly the thermal decoloration reaction [11]. It has been stated that the deviation from solution like behavior in the thermal bleaching reaction are related to the restrictions in the rotation of open MC forms caused by the limited available free volume and the limited chain segment mobility [12]. Polyurethane elastomers hold attention as a host polymer for preparing photochromic polymers due to their some remarkable characteristics such as large strain and high specific energy. Moreover, these elastomers are lightweight, pliable, low manufacturing cost, inexpensive and easily molded into any desirable shapes [13]. These make the polyurethane elastomers very attractive for a wide range of applications such as photochromic response applications. In this paper, we describe the photochromic response of elastomer polyurethane films obtained from a Tecoflex commercial grade and a spiropyran photoprobe. The influence of spiropyran concentration, film thickness and film irradiation are presented. An originality of this work is also to assess the influence of polymer stretching on the photochromic response for a polyurethane grade largely used in medical applications.

\section{Experimental}

\subsection{Materials}

Polymers: The polymer used in this study is a commercial sample of high molecular weight polyurethane which is called Tecoflex-EG100A. Table 1 shows the physical and chemical properties of Tecoflex-EG100A. The glass transition temperature $\left(\mathrm{T}_{\mathrm{g}}\right)$ for this polyurethane grade has been determined using a Viscoanalyser (Metravib VA 2000). The number average molecular weight has been determined by Size Exclusion Chromatography (Waters). Elutions were performed at $35^{\circ} \mathrm{C}$ with tetrahydrofuran (THF) containing di-tertiary-butyl-2.6 methyl-4 phenol as a stabilizer. The flow rate was $1 \mathrm{ml} \cdot \mathrm{min}^{-1}$. The concentration of the polymer solutions and the corresponding injected volumes were 1 g. $1^{-1}$ and $25 \square 1$ respectively. Prior to chromatography, THF and polymer solutions were passed through a Nylon filter of $0.45 \square \mathrm{m}$ porosity. The SEC assembly consisted of a degasser, a Waters 510, Millipore pump, a U6K, Millipore injector, a precolumn, two chromatographic columns assembled in series and filled with line ultrastyragel and an electric oven to control the temperature of the columns. 
Data from the two detectors were acquired and computed by use of the software Astra from Wyatt Technology that allowed determining the molecular weight distribution and the number and weight average molecular weights of the samples.

The other properties were provided by the supplier of the commercial polyurethane.

Solvents: The solvent used to dissolve the Tecoflex-EG100A polyurethane as well as the spiropyran photochromic probe was chloroform (Carlo Erba). The solvents used for the synthesis of the spiropyran probe were used without any further purification (Sigma-Aldrich, pure for synthesis).

\subsection{Spiropyran synthesis}

The spiropyran [1-hexyle-3,3-dimethyl-6'-nitrospiro(indoline-2',2'-benzopyran)] used in this study is synthesized in two stages starting from the 2, 3, 3 trimethylindolenine (T.M.I) which is a commercial product as described by A. Jonquieres [14]. In a first stage (see Figure 2), the requisite quaternary ammonium salt, 1-hexyl-2, 3, 3 trimethylindolenium (TMII) was prepared: a mixture of 2, 3, 3 trimethylindolenine (T.M.I) (0.0316 mol.), 1-iodohexane (Aldrich) (0.0316 mol.) and 100 $\mathrm{mL}$ of acetonitrile (Aldrich) was stirred at $50{ }^{\circ} \mathrm{C}$ with reflux during three days. The solvent is evaporated under vacuum and the crystals are washed in diethyl ether $\left(\mathrm{CH}_{3} \mathrm{CH}_{2} \mathrm{OCH}_{2} \mathrm{CH}_{3}\right)$ at ambient temperature four times. After this, the product is dried under vacuum at $20{ }^{\circ} \mathrm{C}$ during the night. The totality of the product is heated in acetone with reflux because the product is soluble in hot and insoluble in cold. Then, we make a recrystallization of our product with cooling to $20{ }^{\circ} \mathrm{C}$ then to $0{ }^{\circ} \mathrm{C}$ (bath of ice) and the solid collected in Büchner to give a pale yellow product in $50 \%$ yield. The novel operational mode that we propose makes it possible to gain 4 points of output compared to the procedure previously described by Pardal A.C. et al [15] and 3 points compared to that proposed by A. Jonquières et al [14] for obtaining the same compound.

The second stage in the spiropyran synthesis (see Figure 3) corresponds to the generation of "Fischer base ", which is obtained in situ by action of piperidine on the acid proton of the methyl group activated by the quaternary nitrogen atom of the TMII according to a mechanism similar to that described by Samat A. et al [16] for the corresponding benzothiazolic compounds. The nitrosalicylaldehyde reacts on "the basis of Fischer" [17] by a traditional reaction of KNOEVENAGEL [18] followed by an addition of hydroxyl group on heterocyclic carbon as in the following: in a mixture of $0.0113 \mathrm{~mol}$ of TMII in $25 \mathrm{~mL} \mathrm{2-butanone} \mathrm{(Aldrich),} 1.13 \mathrm{~mL}$ of piperidine (Aldrich) was introduced at room temperature, the resulting "Fischer base" was progressively dissolved. 5-Nitosalicylaldyde $(0.0124 \mathrm{~mol})$ (Acros-organics) was then introduced and the reaction mixture was refluxed for 30 minutes, then cooled to room temperature and allowed to stand during the weekend. Then this mixture was hold at $20{ }^{\circ} \mathrm{C}$ during $48 \mathrm{~h}$ in the balloon covered with aluminum foil because the spiropyran is sensitive to the light. Piperidine salts were removed by precipitation in $300 \mathrm{ml}$ of dry diethyether then filtrated, and the crude product was recovered by removing the solvent under reduced pressure.

To eliminate colored impurities, purification was performed by LC on a silica gel column with alcohol-free chloroform as eluant; caution: spiropyran in chloroform is in the blue color open form. At last, the solvent of the different elution fractions was removed by rotary evaporation and the products crystallized in petroleum ether to give $81 \%$ yield a straw yellow (when dried) crystalline pure spiropyran with the structure shown in Figure 4. 


\subsection{Preparation of polyurethane thin films}

As a way of example, $0.6 \mathrm{~g}$ of Tecoflex polyurethane was added to $20 \mathrm{ml}$ of chloroform and the mixture was stirred during 1 hour until the polymer completely dissolved. A very small quantity of photochromic spiropyran (4 mg, $8 \mathrm{mg}, 12 \mathrm{mg}$ and $19 \mathrm{mg}$, depending on the experiment) was then dissolved in the polyurethane solution. The final solution of polyurethane and SP was poured into an aluminum dish and kept at ambient temperature in the dark. After solvent evaporation, the dish was baked in an oven at $60{ }^{\circ} \mathrm{C}$ for 2 hours. The PU/SP film was then peeled off from the dish and its measured thickness was ca. $80 \mu \mathrm{m}$. The resulting films were kept in a dark room to prevent their evolution under direct sunlight prior to the photochromic measurements.

\subsection{Measurement of photochromic response}

The photochromic response is a function of the absorbance characteristics of the photochromic probe incorporated in the polyurethane films. Samples of $60 * 15 *$ thickness (0.037-0.08) millimeters were cut in the PU/SP films using a sharp die. These samples were irradiated using a UV lamp $\left(\lambda_{\max }=365 \mathrm{~nm}\right)$ for various durations (30,60, 120, 240, 360, and 480 seconds) in order to activate the photochromic probe in the polymer matrix. Directly after irradiation, the samples developed a characteristic color and were transferred into an UV-Vis spectrophotometer (Secoman Anthélie Light; LabPowerJ software) using a sample holder specifically designed for this application. The samples were scanned from 400 to $800 \mathrm{~nm}$ at the ambient temperature. For the experiments on the influence of polymer stretching on the photochromic behavior, a manual stretching machine was specifically built-up in our workshop to enable in situ UV-Vis analysis of polyurethane samples at various stretching ratio (Figure 5).

\section{Results and discussion}

\subsection{UV-Vis characterization of the PU/SP films before irradiation 3.1.1 Influence of film thickness for the virgin PU films}

First UV-Vis spectroscopy experiments were carried out with simple polyurethane films. These preliminary experiments enabled to assess the absorbance of the pure polyurethane matrix and can be considered as blank experiments. Measurements of the absorbance spectrum in the visible range (400-800 nm) were carried out for two films with different thicknesses obtained from solutions with different polymer concentrations. Figure 6 presents the absorbance spectra for films with two different thicknesses. Quite unexpectedly, the results show that there is no significant difference in the absorbance of films with thicknesses of 37 and $80 \mu \mathrm{m}$.

In order to confirm this first unexpected observation, new polyurethane films were prepared; leading to a whole set of PU films with thicknesses varying in the range of 20 to $80 \mu \mathrm{m}$. Figure 7 shows the corresponding results for PU films without spiropyran. For this new series of experiments, the absorbance was measured at $576 \mathrm{~nm}$ which corresponded to the maximum absorbance of the SP photochromic probe for the sake of later comparison with the properties of the PU/SP films. This figure confirmed that there was no significant influence of the film thickness on the measured absorption for both series of experiments with unstretched or stretched films. In both cases, the average value of the absorbance was quite low (0.102). A most likely assumption for this surprising behavior is that the polyurethane films without SP acted as strong surfaces of reflection for most of the light of the test lamp and thus made it possible only for a very small part of this light to go through the virgin PU films. Further 'blank' experiments also showed that, as expected, there was no influence of PU irradiation on the absorbance spectra of the pure polyurethane film of $37 \mu \mathrm{m}$ before and after an irradiation of $120 \mathrm{~s}$. 


\subsubsection{Influence of SP concentration for the PU/SP films}

To provide a sound basis for the later analysis of the photochromic behavior of the PU/SP films after irradiation, the UV-Vis absorbance of polyurethane films containing the spiropyran photochromic probe was then investigated without irradiation in order to determine the spiropyran influence on the absorption spectrum when the photochromic probe was in its poorly absorbing closed form (blank experiment).

Therefore, the absorbance spectra of polyurethane films of $80 \mu \mathrm{m}$ were recorded in the wavelength range of 400 to $800 \mathrm{~nm}$ for different spiropyran concentrations. Figure 8 shows that a maximum absorption occurred at ca. $576 \mathrm{~nm}$ in all cases. Figure 9 gives a further illustration of the influence of the spiropyran concentration by showing the absorption measured at $576 \mathrm{~nm}$ as a function of the spiropyran mass ratio in the PU/SP films. This mass ratio was simply defined as the quantity of spiropyran per unit of mass of the polyurethane matrix. It was thus the ratio of the SP mass $(2,4,8$, $10,12,19,50$, and $100 \mathrm{mg}$ ) and the pure polymer mass $(600 \mathrm{mg})$. As expected from Beer-Lambert law, the absorbance increased linearly with the SP mass ratio for the lowest SP mass ratios (typically lower than 0.08). Moreover, from Figure 8, it was obvious that the maximum absorbance for the lowest SP concentration was very close to the absorbance of pure polyurethane, as it has been shown in section 3.1.1. But with increasing the SP concentration, the maximum absorbance increased significantly because it accounted for the absorbance of both the pure polyurethane and the SP probe at $576 \mathrm{~nm}$. Furthermore, for the highest spiropyran concentration, the behavior was no more linear and the absorbance did not obey Beer-Lambert law anymore.

Notice that even when the sample had not been irradiated, some SP related absorbance was thus observed, despite the fact that precautions were taken to avoid activating the photochrome before measurement. This absorbance can be attributed at least partly to a solvatochromism phenomenon. In that case, a solvent or matrix effect can be responsible for a weak equilibrium between the spiropyrane (colorless) and the merocyanine (colored) forms. This balance can be modified by the solvent or matrix polarity, polar solvents being known to displace the equilibrium towards the merocyanine formation. In this way, it is possible that the polymer matrix polarity leads to a small photochrome absorbance even when the polymer sample has not yet been irradiated [19].

\subsubsection{Influence of PU/SP film thickness}

PU/SP films of Tecoflex-EG100A with various thicknesses $(38,45,62,71$, and $80 \mu \mathrm{m})$ and the same very low mass fraction of SP (0.0067) were then investigated to study the influence of film thickness on the maximum absorbance in the visible range without irradiation. Complementary related spectroscopy experiments were also carried out with stretched films. For the latter experiments, a test PU/SP film of $80 \mu \mathrm{m}$ thickness was stretched to different ratios $(0,15,30,50$, 100 and $150 \%$ ) corresponding to a film thickness decrease from $80 \mu \mathrm{m}$ to $38 \mu \mathrm{m}$ at $0 \%$ and $150 \%$ stretching, respectively. As shown in Figure 10, all the stretched and unstretched PU/SP films displayed the same behavior with a very low increase of the maximum absorbance when the film thickness increased. Moreover, the maximum absorbance of all the tested PU/SP films without irradiation was systematically very close to that of the corresponding virgin PU films, confirming again the very low absorbance related to the closed spiropyran probe in such a low amount.3.2. Photochromic behavior of the PU/SP films after irradiation after exposure to ultraviolet light, the spiropyran $\mathrm{C}-\mathrm{O}$ bond is cleaved and the photochromic probe becomes a metastable zwitterionic highly colored merocyanine (Figure 1 ). The $\mathrm{C}-\mathrm{O}$ bond cleavage leads to the rotation of the nitrophenyl ring and to the conversion to a planar molecular structure. The cis form is extremely unstable and will either transform into a trans structure or be converted back to the spiropyran initial form. The trans structures correspond in fact to four different isomers depending on the 
rotation. When the spiropyran probe is dissolved in a polyurethane film and excited by UV, four trans isomers can thus be obtained with different distances between the zwitterions $\mathrm{N}^{+}$and $\mathrm{O}^{-}$ corresponding to different activation energies. The shorter the distance between $\mathrm{N}^{+}$and $\mathrm{O}^{-}$, the higher the exciting activation energy. However, these four activation energies are close according to Heiligman-Rim et al. [20]. In this work, the focus is made on the analysis of absorbance spectra obtained in different conditions, which thus reflect the total absorption of the different merocyanine isomers in the following referred to as "merocyanine" for the sake of simplicity.

In the following, the absorbance spectra of PU/SP films after irradiation are analyzed as a function of irradiation time, film stretching and discoloration time for the same SP mass ratio of 0.0067 . This very low amount of SP was chosen to minimize the deviation from linearity observed at higher SP concentrations (see section 3.1.2). Complementary experiments will also be discussed to assess the influence of SP concentration on the photochromic behavior after irradiation.

\subsubsection{Influence of irradiation time}

To study the effect of the irradiation time on the photochromic properties of Tecoflex-EG100A films with SP mass fraction of 0.0067, the PU/SP films were irradiated with a UV lamp at $365 \mathrm{~nm}$ for different periods of time varying from 0 up to 480 seconds. The initially colorless films became violet after irradiation and the absorbance spectra were recorded immediately in the wavelength range of 400 to $800 \mathrm{~nm}$ (Figure 11).

In good agreement with the observations reported in Figure 8 of section 3.1.2, Figure 11 shows that the absorbance of the PU/SP film before irradiation was very low. On the contrary, a moderate to strong absorption peak was systematically obtained under $365 \mathrm{~nm}$ irradiation. The maximum absorption occurred at $576 \mathrm{~nm}$ and did not depend significantly upon the irradiation time. According to the solvatochromism effect, the wavelength of this maximum absorption is governed by the sample polarity and can be correlated to the Dimroth and Reichardt's polarity scale [14]. Nevertheless, the intensity corresponding to the maximum absorbance strongly increased with the irradiation time. For this very low concentration of spiropyran, the spectrophotometer detector became saturated after 480 seconds irradiation time as clearly shown by the top curve in Figure 11. This sharp increase in absorption intensity corresponds to an increase in the concentration of the highly colored merocyanine with the irradiation time.

Figure 12 shows the results of the same type of experiments carried out with increasing SP mass ratios $(0.0033,0.0067,0.0133,0.0167,0.02$, and 0.0317) in the Tecoflex-EG100A films. For each SP concentration, the intensity corresponding to the maximum absorbance was determined at different irradiation times between 0 and 480 seconds. The unmeaning intensity data corresponding to a saturation of the spectrophotometer detector were not reported in this new Figure. Therefore, no data were reported for an irradiation time of 480 seconds for all the samples and also for 360 seconds for the samples containing the highest amounts of spiropyran (SP mass ratio > 0.0067). Figure 12 clearly shows that the maximum intensity sharply increased with the irradiation time whatever the SP concentration. An interesting observation is that this increase was not linear. All the curves describing the variation of this intensity as a function of irradiation time clearly showed that the influence of irradiation time decreased at high irradiation times.

To conclude on this part, the irradiation of PU/SP films led to highly colored films and the saturation of the spectrophotometer detector was readily achieved at high irradiation times even for very low SP concentrations. As expected, increasing the SP concentration led to a quicker saturation. Therefore, these experiments enabled to determine the useful range for an appropriate 
investigation of the photochromic behavior corresponding to very low SP concentrations and moderate irradiation times.

\subsubsection{Influence of SP concentration}

Replotted from the experimental data reported in the latter section, Figure 13 focuses on the influence of the SP concentration on the maximum absorbance of PU/SP films for increasing irradiation times. Figure 13 clearly shows that the maximum absorption increases with the SP concentration. This increase in the photochromic response was expected because the higher the SP concentration, the higher the conversion to the colored merocyanine during irradiation.

Nevertheless, Figure 13 also shows that the PU/SP maximum absorbance did not vary linearly with the SP concentration. The maximum absorbance for the polyurethane without SP was approximately 0.1 (see section 3.1.1) but it increased very sharply when a small amount of SP was added to the polymer. This non linearity of the maximum absorbance-SP concentration relationship cannot be accounted for by the simple Beer-Lambert law. At this stage, it is reminded that BeerLambert law is generally used to account for the absorbance of a solute in solution. This is quite different from the absorbance of a solute dissolved in a solid phase which corresponds to this work. The modeling of the PU/SP maximum absorbance as a function of SP concentration is the subject of another related investigation which will be reported shortly.

\subsubsection{Influence of PU/SP film thickness}

Following the investigation of the influence of film thickness on the PU/SP maximum absorbance before irradiation reported in section 3.2, Figure 14 shows the maximum absorbance for the same films after an irradiation of 60 seconds. The same general trend was observed before and after irradiation with an increase of the maximum absorbance with film thickness. The increase in film thickness typically corresponded to an increase in optical path responsible for an increase in the film absorbance. Nevertheless, it was also responsible for a decrease in the irradiation energy absorbed by the polymer film per unit of polymer volume which thus corresponded to a decrease in the spiropyran to merocyanine photoconversion. The net positive effect of an increase in film thickness was thus the result of a compromise between both phenomena.

Moreover and as expected, the maximum absorbance of the irradiated films was systematically much higher than for the non irradiated films. A comparison between Figure 10 and Figure 14 indicates that the slope of the straight line describing the variation of the maximum absorbance as a function of film thickness within the range of investigation (38 to $80 \mu \mathrm{m})$ was much higher (+ 73 $\%)$ for the irradiated films compared to that obtained for the same films before irradiation. Therefore, the influence of film thickness appeared much higher after than before irradiation. Lastly, even if the variation of the maximum absorbance was linear within the range of interest, the intercept of the corresponding straight line appeared meaningless. Therefore, the influence of film thickness on the maximum absorbance could certainly not be accounted for by a linear relationship for the whole range of film thicknesses.

\subsubsection{Influence of film stretching}

According to the best of our knowledge, related works on the influence of polymer stretching on the photochromic behavior of spiropyrans are really scarce in the literature. Smets et al. reported the influence of polymer stretching on the kinetics of discoloration of highly bulky spiropyran derivatives $[10,11]$. In the former works, the authors stretched the polymer films at $60{ }^{\circ} \mathrm{C}$ after annealing for 15 minutes. The stretched films were then stored for one month to avoid relaxation 
effects before sample irradiation and photochromic characterization. In these particular conditions, it was shown that polymer stretching slowed down the discoloration rate.

In this work, the stretching was performed at ambient temperature with the manual stretching machine depicted in Figure 2 for Tecoflex-EG100A films containing 0.0067 mass fraction of spiropyran. The photochromic behavior was analyzed within a short period of time to minimize the relaxation effects and obtain experimental data which reflect the influence of initial stretching on the photochromic behavior. Two kinds of experiments were carried out. In the first series of experiments (first case), the PU/SP films were irradiated first during 60 seconds and then stretched at different stretching ratios $(0 \%, 15 \%, 30 \%, 50 \%, 100 \%$ and 150\%). In the second series of experiments (second case), the PU/SP films were stretched first and then irradiated for the same period of time of 60 seconds. Figure 15 shows the influence of stretching in the first case corresponding to stretching after irradiation. A waiting time of 4 minutes before recording the spectra was required for allowing the transfer of the sample carrier in the spectrophotometer and the initialization of the measurement program.

As a general trend, the maximum absorbance decreased strongly when the stretching ratio increased after irradiating the samples for 60 seconds. The influence of polymer stretching on the maximum absorbance was already significant even for the lowest stretching ratio of $15 \%$ and remained strong for higher stretching ratios up to $100 \%$. For the maximum stretching ratio of 150 $\%$, this influence decreased significantly most likely in relation to the polymer mechanical behavior under stretching. Polymer stretching led to a decrease in film thickness which was responsible for a decrease in film absorbance. In this first case which corresponds to very different conditions compared to those reported in the former related works by Smets et al. $[10,11]$, the polymer stretching after irradiation was also certainly responsible for a mechanical stress on the merocyanine open forms which facilitated the merocyanine to spiropyran photoconversion. Both phenomena eventually contributed to the overall decrease of the absorbance shown in figure 15 . New PU/SP films were then prepared for the second series of experiments in order to avoid any risk of film degradation. Figure 16 shows the influence of stretching in the second case corresponding to stretching before irradiation. For the sake of comparison, the irradiation and waiting times before spectra recording were kept identical as those in the first series of experiments (60 s and $4 \mathrm{~min}$, respectively). Here again, the maximum absorbance decreased with increasing the stretching ratio. Nevertheless, this decrease was much lower when the irradiation was performed after rather than before stretching. Therefore, the influence of polymer stretching on the maximum absorbance was strongly minimized when it was anterior to the sample irradiation.

In the second case like in the first case, the decrease of maximum absorbance was partly due to a decrease in film thickness. Nevertheless, in the second case, the irradiation of a much thinner film (i.e. the film after stretching) led to a stronger spiropyran to merocyanine photoconversion owing to a much stronger irradiation energy per unit of film thickness [21-24]. The later effect was thus responsible for an increase in the maximum absorbance. The spectra in Figure 16 thus accounted for both antagonist effects with a net result corresponding to a much lower decrease in the maximum absorbance as a function of polymer stretching as compared to Figure 15. Figure 17 confirms this assumption by showing that the difference in the maximum absorbances for both cases significantly increased when the thickness of the polymer film after stretching decreased, thus corresponding to a stronger irradiation energy per unit of film thickness and to a better initial photoconversion of spiropyran to merocyanine. 
The influence of polymer stretching on the discoloration kinetics was then investigated. For performing this last series of experiments, polymer films containing a spiropyran mass fraction of 0.0067 were irradiated during 60 seconds and then stretched with different stretching ratios $(0,15$, 30,50 , and $150 \%$ ). The choice of these experimental conditions was motivated by the fact that the influence of polymer stretching on the photochromic behaviour was much stronger when the irradiation was performed before rather than after polymer stretching (figure 17).

Figure 18 shows the discoloration curves of PU/SP films at different stretching ratio. It is reminded that a minimum waiting time of 4 minutes was necessary for the transfer of the sample carrier into the spectrophotometer and the initialization of the measurement program for all the stretched samples. Therefore, this imposed delay did not enable to record the initial maximum absorbance for the discoloration curves of the stretched films. Nevertheless, Figure 18 shows that the maximum absorbance recorded for the different samples decreased with an increase of the stretching ratio at the same discoloration time. This observation is in good agreement with the data reported in Figure 15 corresponding to a particular discoloration time (4 minutes). Owing to the fact that the initial absorbance could not be determined for the stretched films, it is difficult to assess the initial discoloration rate without developing an appropriate model. Nevertheless, the discoloration curves in Figure 18 show relatively similar trends with close discoloration rates. After one hour of discoloration, the maximum absorbances were strongly decreased and fairly close to those measured for the same stretching ratios without irradiation (section 3.1.3). In this work, the discoloration rates thus appeared quite high and apparently relatively insensitive to the polymer stretching ratio.

Smets et al have reported related data on the influence of polymer stretching on the discoloration rate of highly bulky spiropyran derivatives in polyester films after stretching and one month of film relaxation before irradiation $[10,11]$. With these highly bulky spiropyran derivatives, the authors found much lower discoloration rates than those observed in this work. For example, with spiropyran derivatives containing oligomer side chains, a discoloration of $59 \%$ only was obtained after 44 hours for a stretching ratio of $100 \%$. The authors also showed that the discoloration rate depended strongly upon the molecular size of the photochromic probe and, to a less extent, upon its molecular orientation by polymer stretching. It was assumed that the merocyanine to spiropyran photoconversion was limited by the mechanical effects induced by polymer stretching. A comparison with the results obtained in this work shows great differences in the photochromic behaviors. These differences could be ascribed to very different experimental conditions and to the high steric hindrance of the spiropyran derivatives used by Smets et al. which strongly reduced their discoloration rates.

\section{Conclusion}

The first part of this work focused on the UV-Vis characterization of polyurethane films containing increasing amounts of a spiropyran photochromic probe before irradiation. The maximum absorbance increased linearly with the spiropyran mass fraction in the low range of photochrome concentration and the intercept corresponded to the maximum absorbance of the virgin polyurethane. Nevertheless and as expected, a deviation from the Beer-Lambert law was observed for much higher spiropyran mass fractions (>0.08). The influence of film thickness on the maximum absorbance was extremely low for the virgin PU film and still quite low for a PU film with a very low spiropyran mass fraction $(0.0067)$ chosen in the linearity range. All of these results confirmed as expected the very low absorbance related to the closed spiropyran probe in very low amount. Corresponding to a series of "blank" experiments, these first results provided a basis for the investigation of the photochromic behavior after irradiation. 
The second part of this work analyzed the photochromic properties of PU/SP films after irradiation in various experimental conditions. In any case, the irradiation was responsible for a strong coloration of the films corresponding to the spiropyran to merocyanine photoconversion. The maximum absorbance strongly depended upon the different experimental parameters (irradiation time, SP mass fraction, film thickness and stretching). The irradiation time had to be limited to 60 seconds to obtain reasonable maximum absorbances typically less than 1.5. The influence of SP concentration on the maximum absorbance appeared more complex than before irradiation and could no more be accounted for by a simple Beer-Lambert law. The maximum absorbance varied linearly with the PU/SP film thickness in the range of investigation (40 to $80 \square \mathrm{m}$ ) but the corresponding intercept appeared meaningless. The influence of polymer stretching on the maximum absorbance was fairly strong when the stretching was performed after irradiation. When the stretching was performed before irradiation, its influence was much weaker. In all cases, the polymer stretching induced a decrease in the maximum absorbance partly due to the corresponding decrease in film thickness.

However, in the later case, the decreased thickness of the stretched films under irradiation was also responsible for a much stronger spiropyran to merocyanine photoconversion which strongly reduced the final decrease in the measured absorbance after polymer stretching. On the other hand, the discoloration rates appeared relatively insensitive to the polymer stretching for the systems investigated in this work most likely owing to the relatively low molecular weight of the spiropyran photochromic probe. The last results regarding the influence of polymer stretching on the maximum absorbance open the way for determining stretching ratios and local compression from photochromic measurements with a wide range of potential applications. Of particular interest in this context are the textiles used for biomedical applications, including graduated compression stockings for preventing or treating deep vein thrombosis. Another related application is the recent development of special sport clothing for improving recovery after strong efforts.

\section{References}

[1] E. Fischer, Y. Hirshberg, Formation of colored forms of spirans by low-temperature irradiation, Journal of the Chemical Society (1952) 4522-4524.

[2] V. A. Barachevsky, Synthetic and natural organic photochromic systems for optic application, International journal of Photoenergy 1(1999) 191-195.

[3] S. Kawata, Y. Kawata, Three-dimensional optical data storage using photochromic materials, Chemical Reviews 100(2000) 1777-1788.

[4] Y. Yokoyama, Fulgides for memories and switches, Chemical Reviews 100(2000) 1717-1739.

[5] M. Irie, Diarylethenes for memories and switches, Chemical Reviews 100(2000) 1685-1716.

[6] O. Pieroni, A. Fissi, F. Ciardelli, Photochromic poly (alpha-amino acid)s: photomodulation of molecular and supramolecular structure, Reactive \& Functional Polymers 26(1995) 185199.

[7] A. Samoladas, A. Jannakoudakis, D. Bikiaris, K. Chrissafis, K. M. Paraskevopoulos, Effect of end group content on photochromic behavior of spiropyran in polycaprolactonepoly(ethylene succinate) blends, Journal of Applied Polymer Science 105(2007) 3623-3633.

[8] G. Smets, J. Thoen, A. Aerts, Some photochemical reactions in solid polymer systems, Journal of Polymer Science: Polymer Symposia 51(1975) 119-134. 
[9] M. Kryszewski, D. Laoienis, B. Nadolski, Mechanism of thermal decolorization of benzospirans in some amorphous polymetric matrices, Journal of polymer science: polymer chemistry edition 11(1973) 2423-2436.

[10] G. Smets, New developments in photochromic polymers, Journal of Polymer Science: Polymer Chemistry Edition 13(1975) 2223-2231.

[11] G. Smets, J. Braeken, M. Irie, Photomechanical effects in photochromic systems, Pure and Applied Chemistry 50(1978) 845-856.

[12]C. D. Eisenbach, Comment on the matrix effect on photochromism of Spiropyrans in bulk polymers, Polymer Bulletin 2(1980) 169-176.

[13] I. Diaconu, D. Dorohoi, Properties of polyurethane thin films, Journal of optoelectronics and advanced materials 7(2005) 921-924.

[14] A. Jonquieres, D. Roizard, J. Cuny, A. Vicherat, P. Lochon, Polarity measurements in block copolymers (polyurethaneimides) and correlation with their pervaporation features, Journal of Applied Polymer Science 56(1995) 1567-1579.

[15] A. C. Pardal, S. S. Ramos, P. F. Santos, L. V. Reis, P. Almeida, Synthesis and spectroscopic characterization of $\mathrm{N}$-alkyl quaternary Ammonium salts typical precursors of cyanines, Molecules 7(2002) 320-330.

[16] A. Samate, R. Guglielmetti, J. Metzger, Synthesis of a series of 3-substituted photochromic benzothiazoline spirobenzopyrans, Helvetica Chimica Acta 55(1972) 1782-1801.

[17] T. Shimidzu, M. Yoshikawa, Photo-induced carrier mediated transport of alkali metal salts, Journal of Membrane Science 13(1983) 1-13.

[18] J. March, Advanced organic chemistry. Reactions, mechanisms, and structure, 3nd Ed. John Wiley and Sons 1985.

[19] J.-S. Lin, H.-T. Chiu, Photochromic behavior of Spiropyran and Fulgide in thin films of blends of PMMA and SBS, Journal of Polymer Research 10(2003) 105-110.

[20] R. Heiligman-Rim, Y. Hirshberg, E. Fischer, Photochromism in Spiropyrans. V. the mechanism of phototransformation. Journal of Physical Chemistry 66(1962) 2470-2477.

[21] L.S. Atabekyan, G.V. Zakharova, A.K. Chibisov, Photochromic transformations of Spiro compounds: 1. a new approach to determining the photocoloration quantum yield, High Energy Chemistry (Translation of Khimiya Vysokikh Energii) 2001; 35: 349-354.

[22] L.S. Atabekyan, G.V. Zakharova, V.N. Ogienko, A.K. Chibisov, Photochromic transformations of Spiro compounds: 2. the kinetics of photocoloration under continuous irradiation, High Energy Chemistry (Translation of Khimiya Vysokikh Energii) 36(2002) 322-325.

[23] M. Maafi, Useful spectrokinetic methods for the investigation of photochromic and thermophotochromic Spiropyrans, Molecules 13(2008) 2260-2302.

[24] G. Ottavi, F. Ortica, G. Favaro, Photokinetic methods: a mathematical analysis of the rate equations in photochromic systems, International Journal of Chemical Kinetics 31(1999) 303-313. 


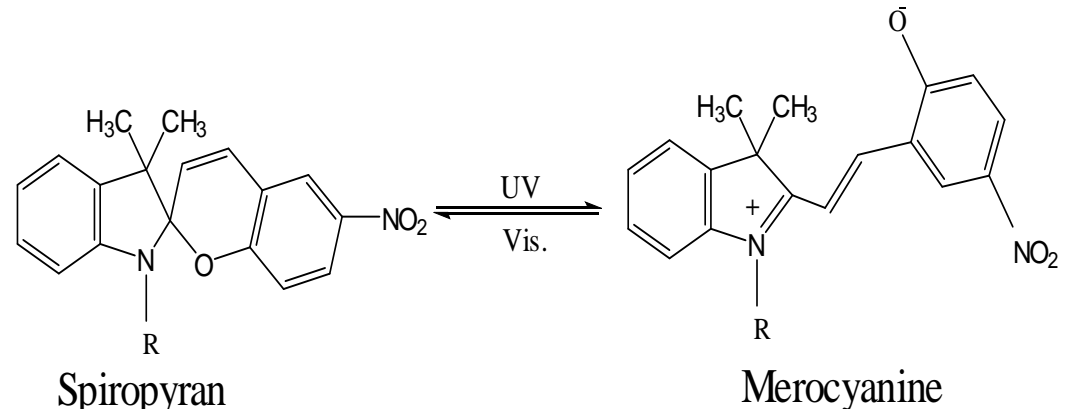

Figure 1: Example of the chemical structure of a photochromic SP molecule and its isomer merocyanine colored form.<smiles></smiles>

2,3,3-trim e th y lindolenine

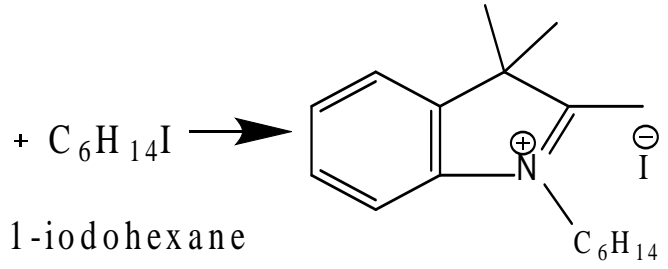

T M II

TM I

Figure 2: First synthesis step of the spiropyran dye<smiles>CCCCCN1C(=O)C(C)(C)c2ccccc21</smiles><smiles>C=CCN1C(=C)C(C)(C)c2ccccc21</smiles>
M I

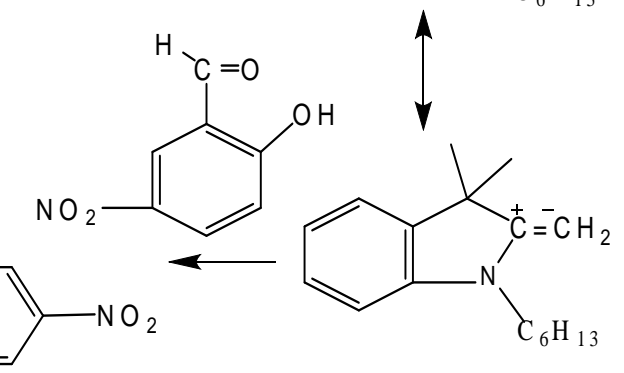

Fischer's base S piropyran

Figure 3: Principle of the second synthesis step of the spiropyran 


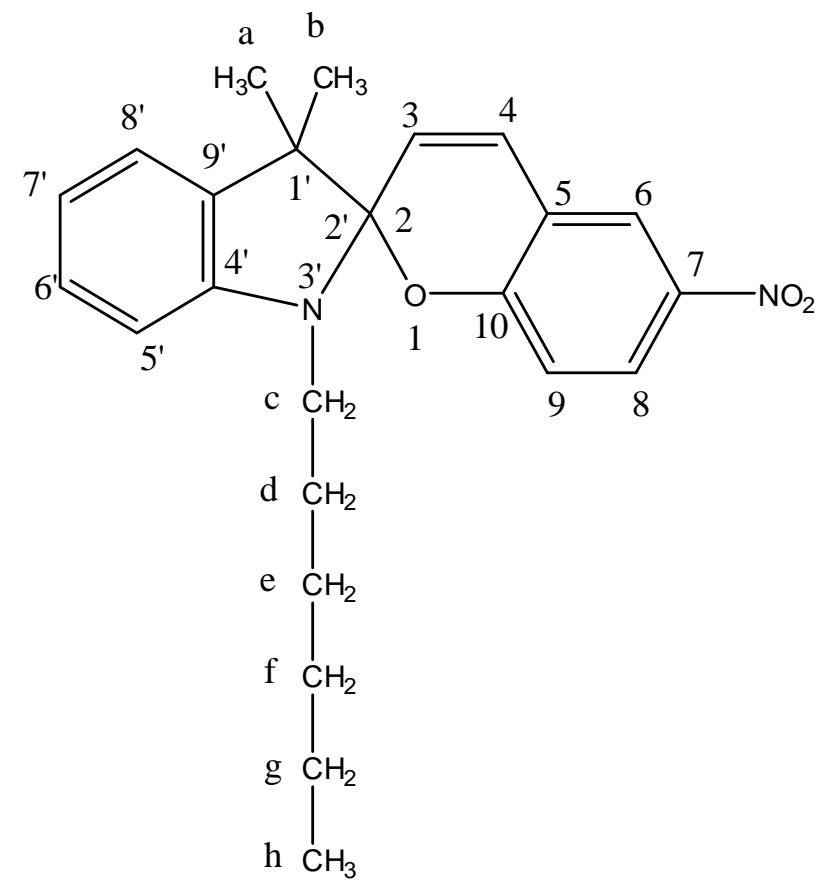

Figure 4: $\mathrm{H}$ and $\mathrm{C}$ indexing for spiropyran NMR characterization

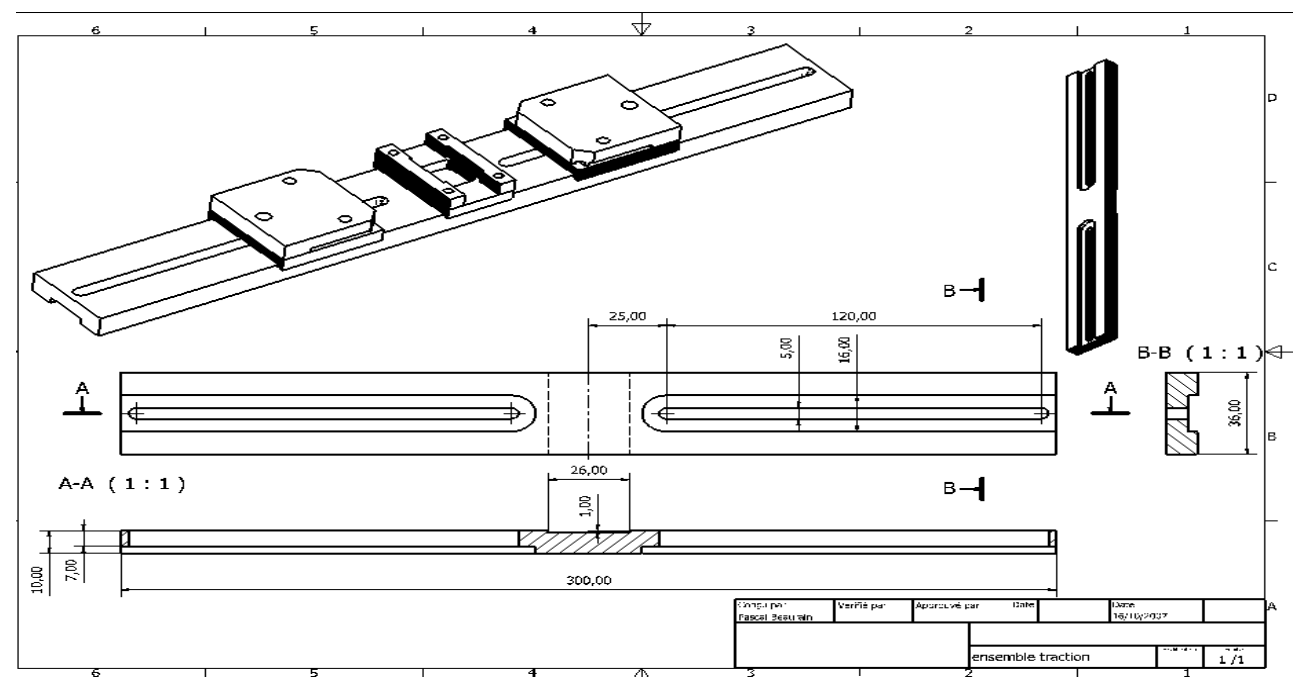

Figure 5: Scheme of the manual stretching machine 


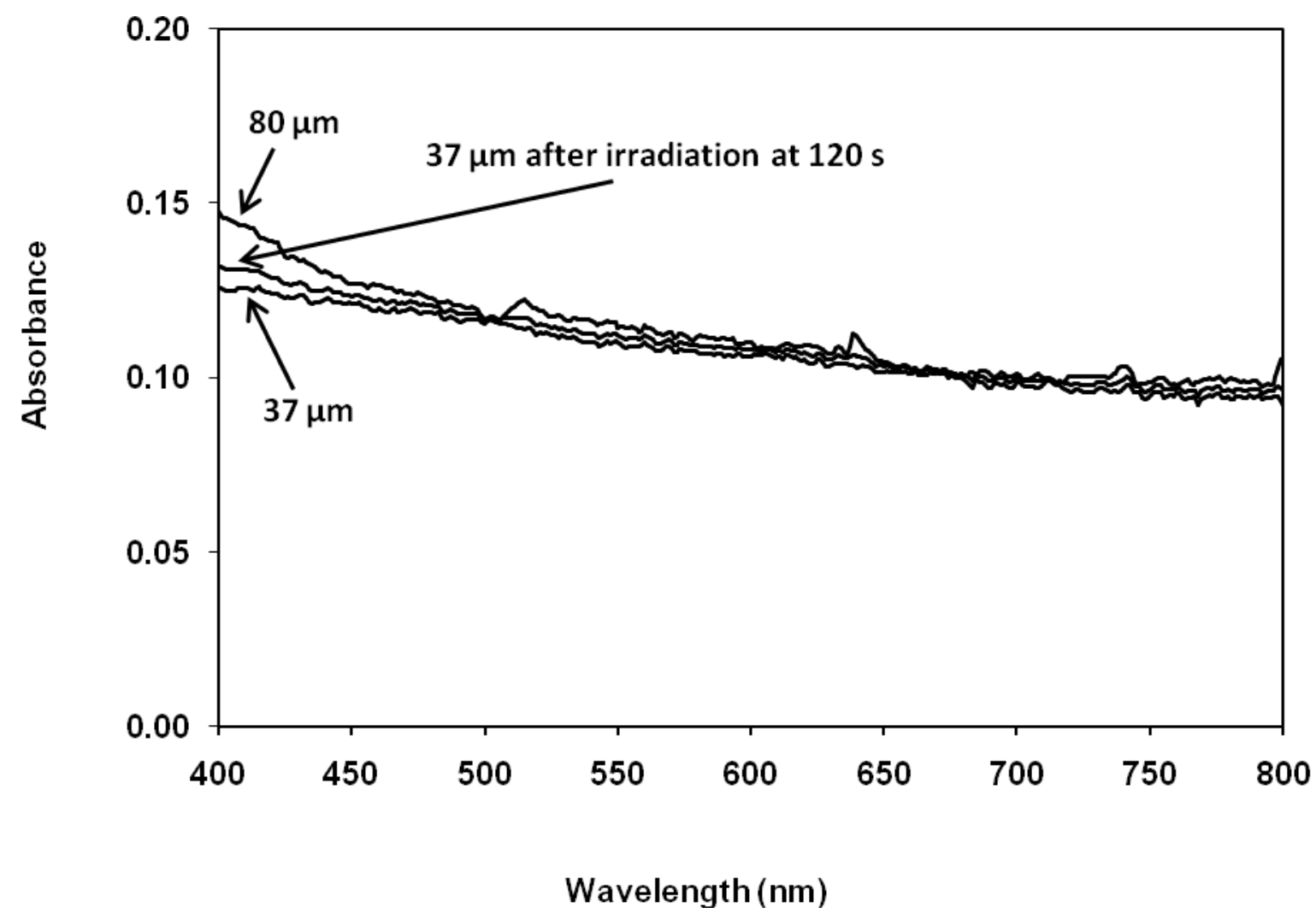

Figure 6: Absorbance spectra for Tecoflex-EG100A films

with different film thicknesses (37 and $80 \mu \mathrm{m})$ without spiropyran

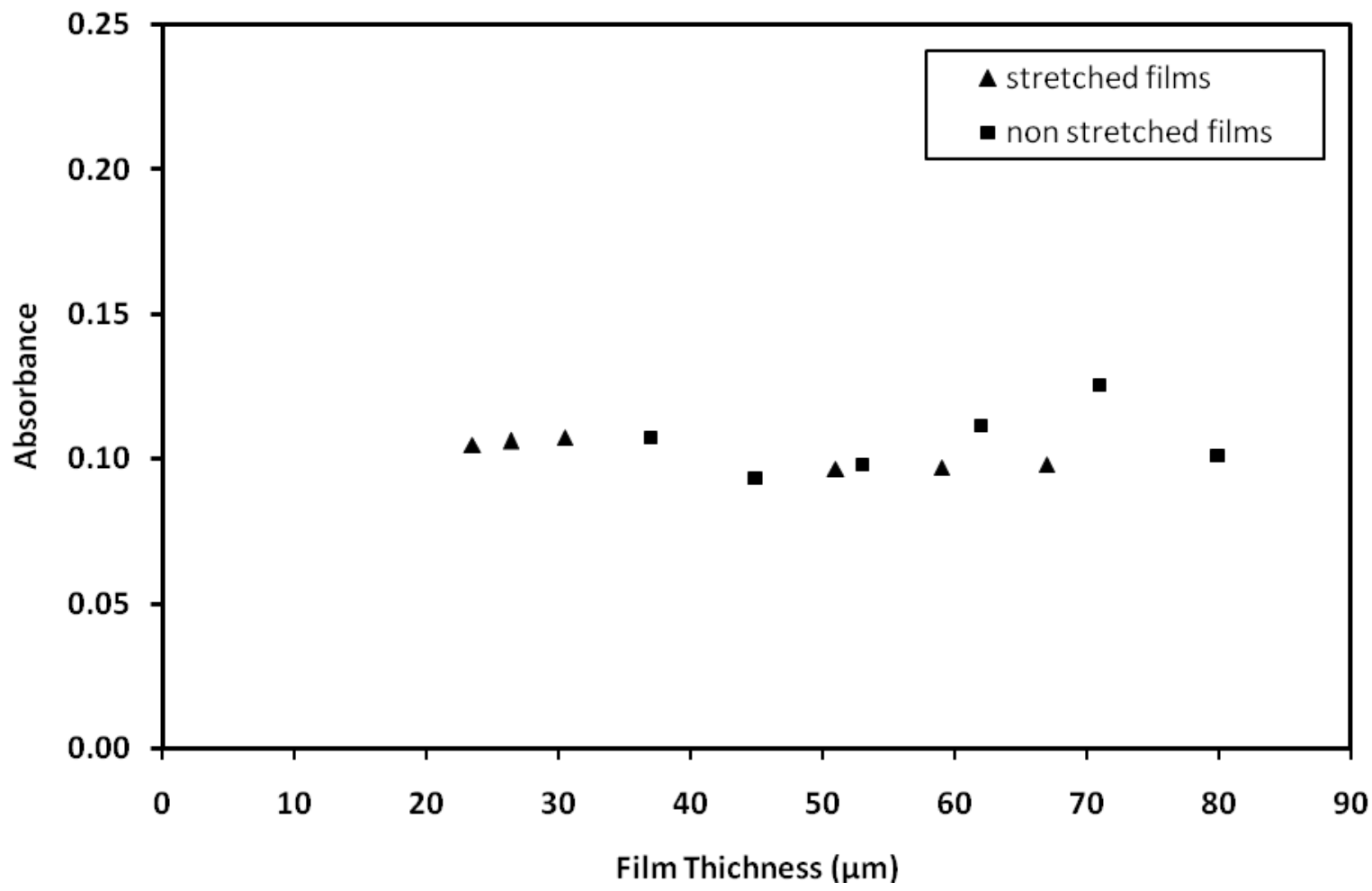

Figure 7: Influence of film thickness on the absorbance at $576 \mathrm{~nm}$ for unstretched and stretched films of Tecoflex-EG100A without spiropyran 


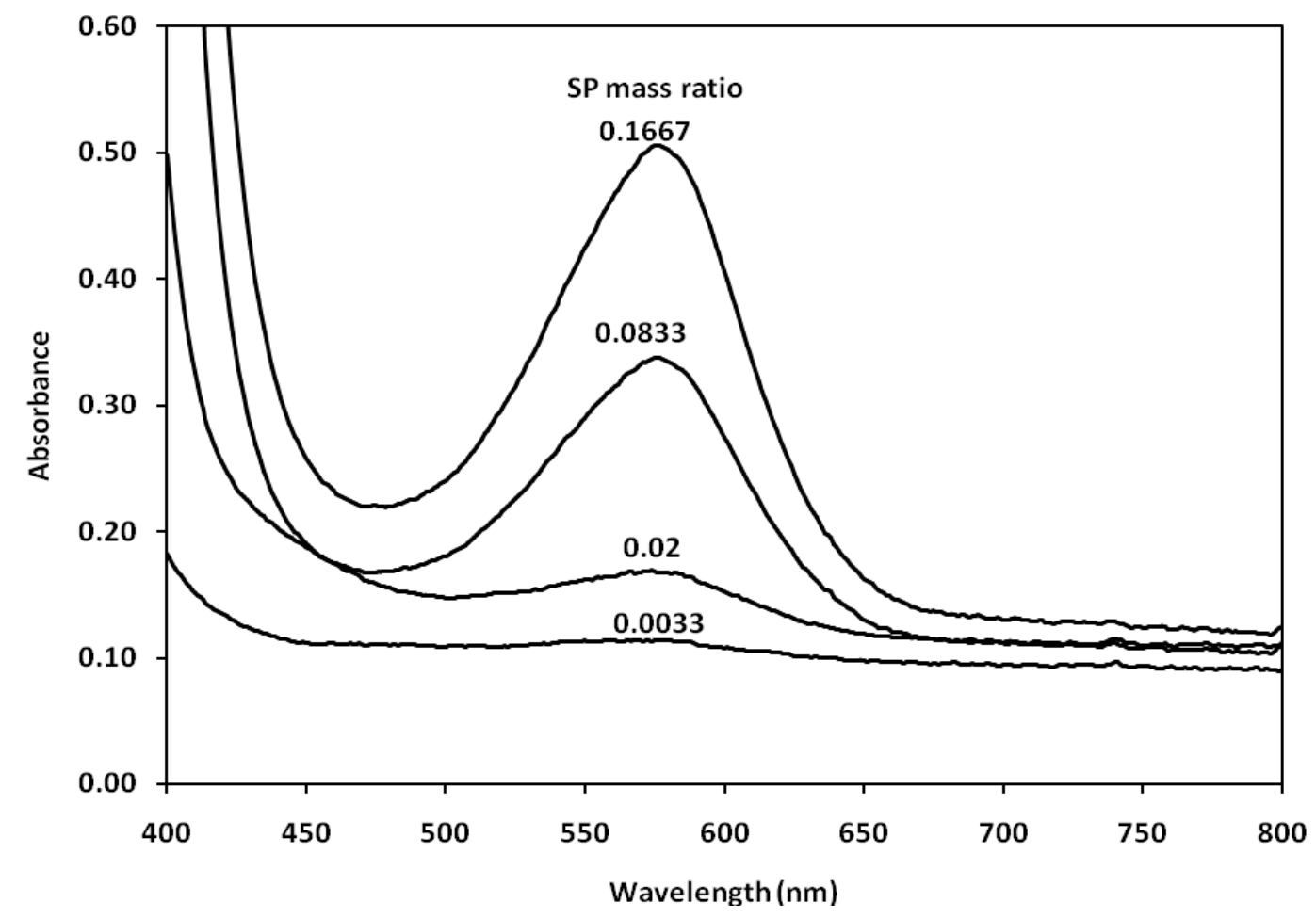

Figure 8: Characteristic examples for the UV-Vis absorption spectra UV-Vis of PU/SP films of $80 \mu \mathrm{m}$ with different spiropyran concentrations and no irradiation.

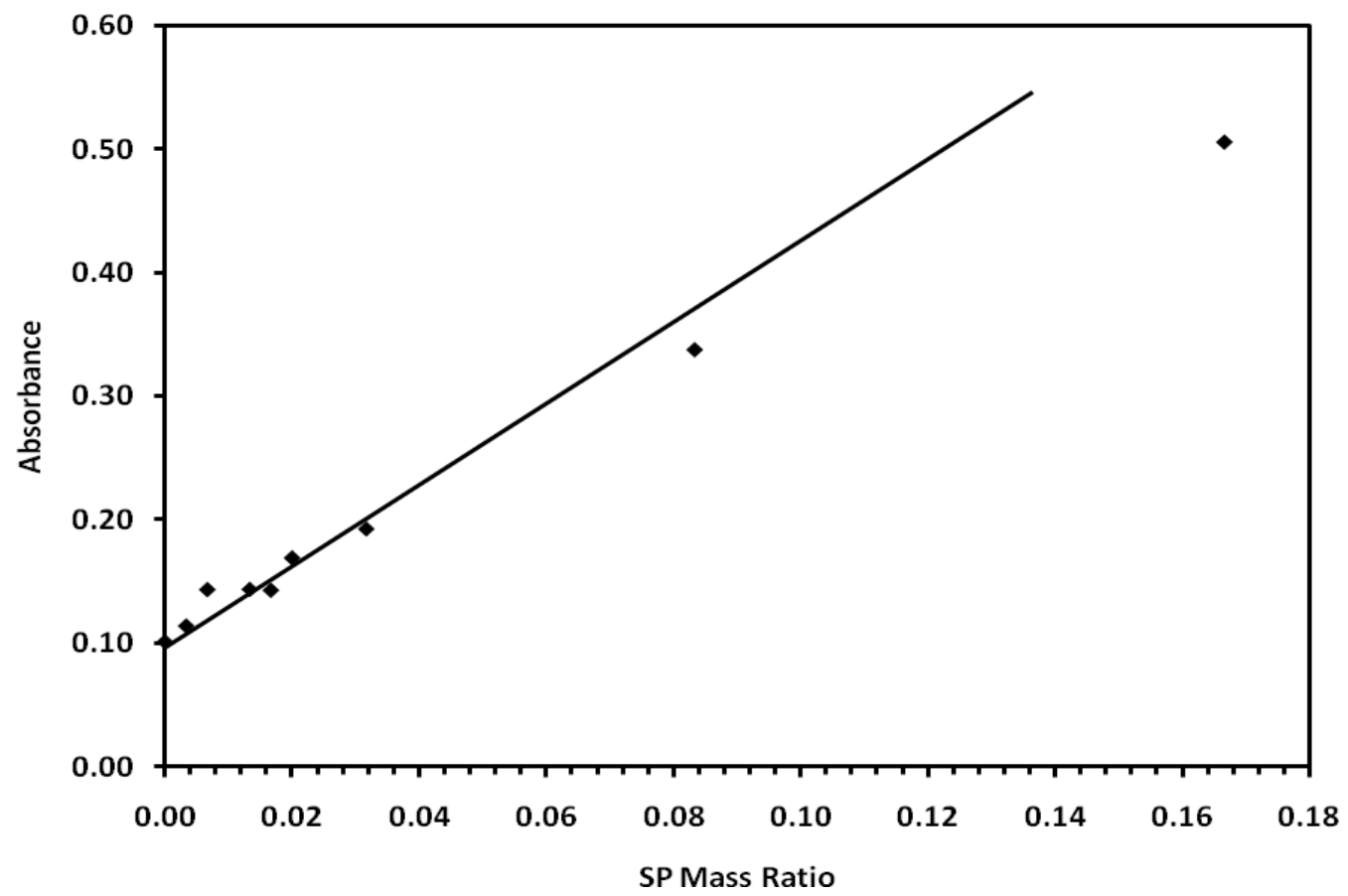

Figure 9: Influence of SP concentration on the absorbance at $576 \mathrm{~nm}$ for PU/SP films of $80 \mu \mathrm{m}$. 


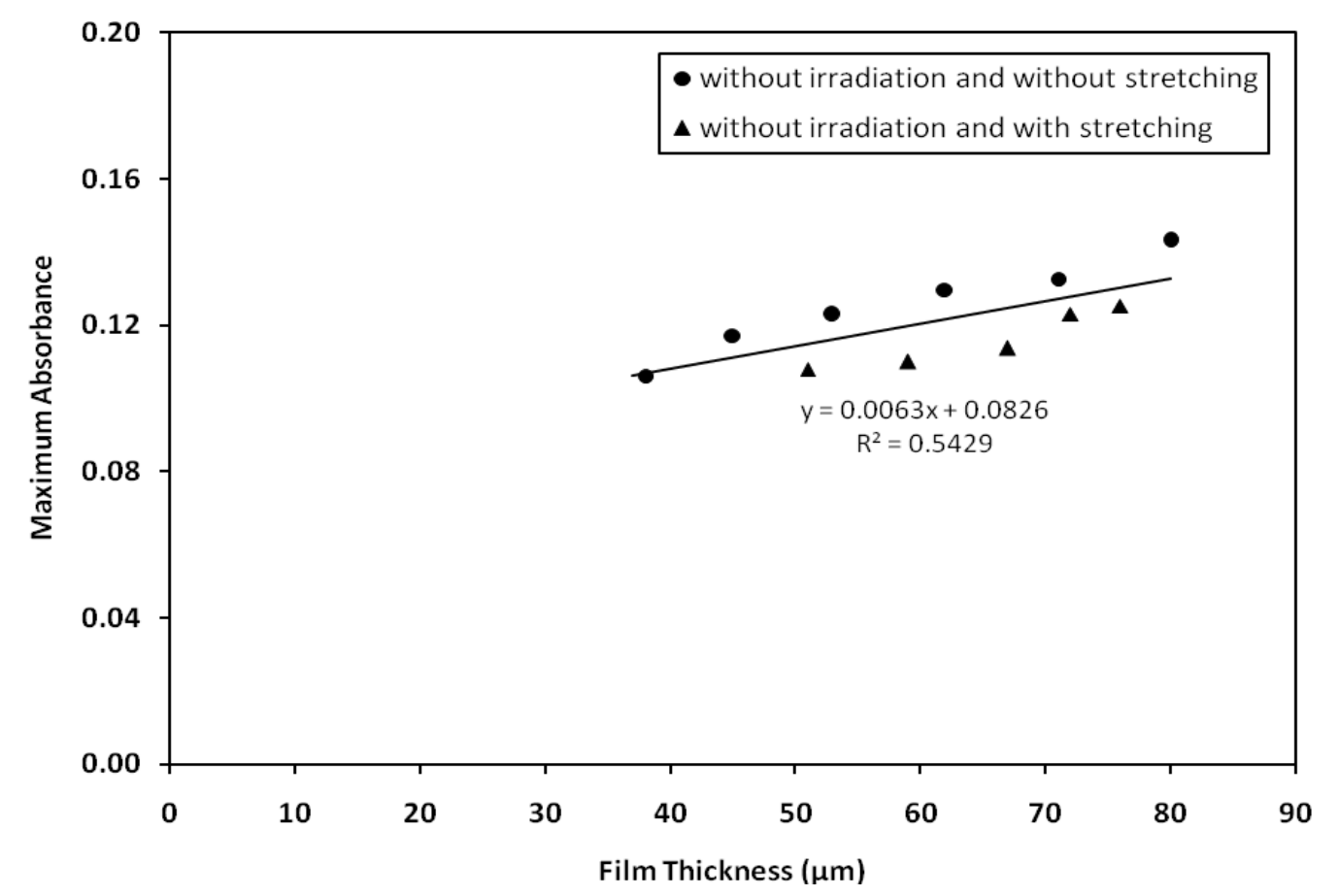

Figure 10: Influence of the thickness of stretched and unstretched films on the maximum absorbance (Films: Tecoflex-EG100A with SP mass ratio of 0.0067)

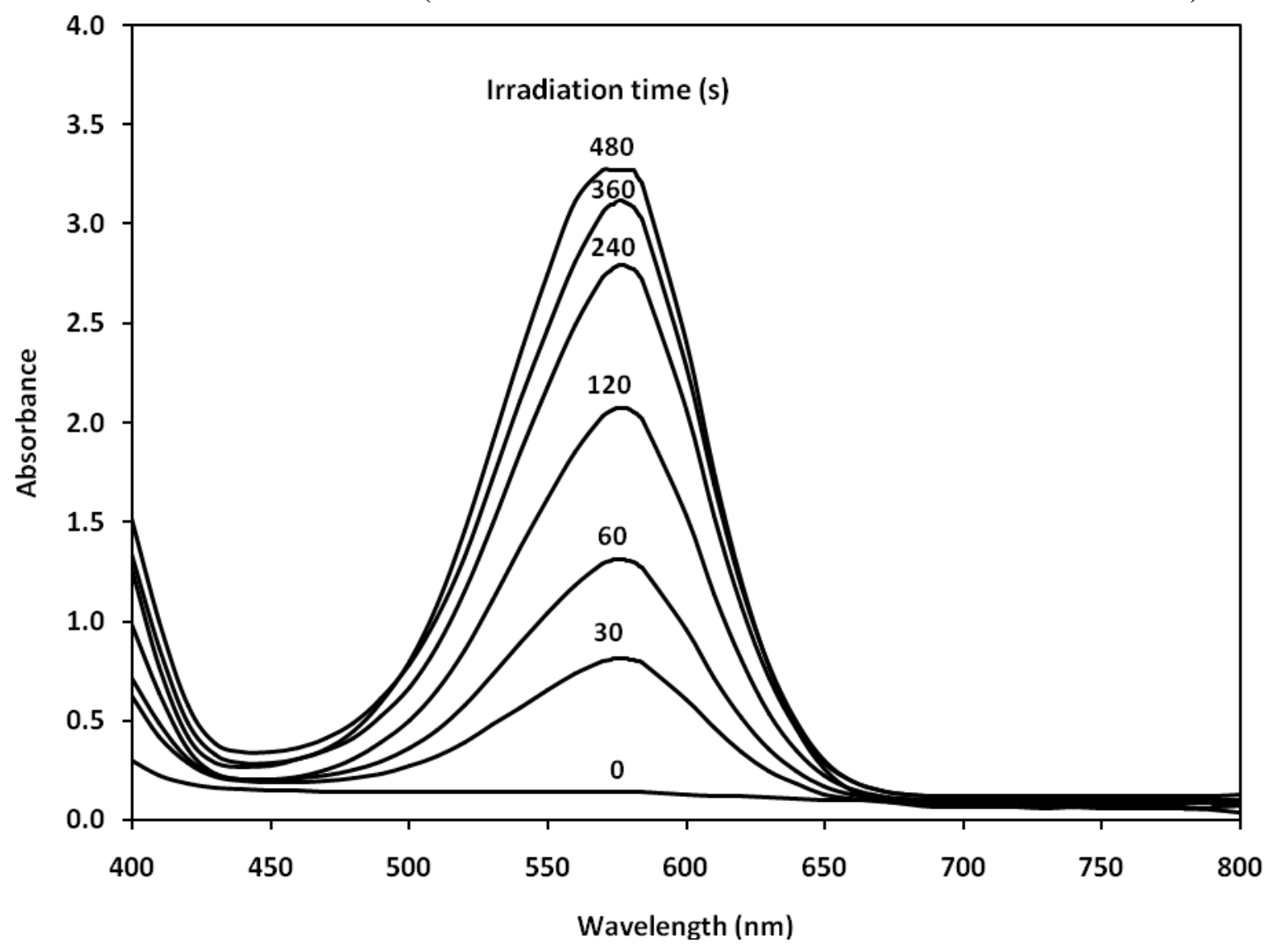

Figure 11: Influence of irradiation time on the maximum absorbance spectra for Tecoflex-EG100A films with SP mass ratio of 0.0067 . 


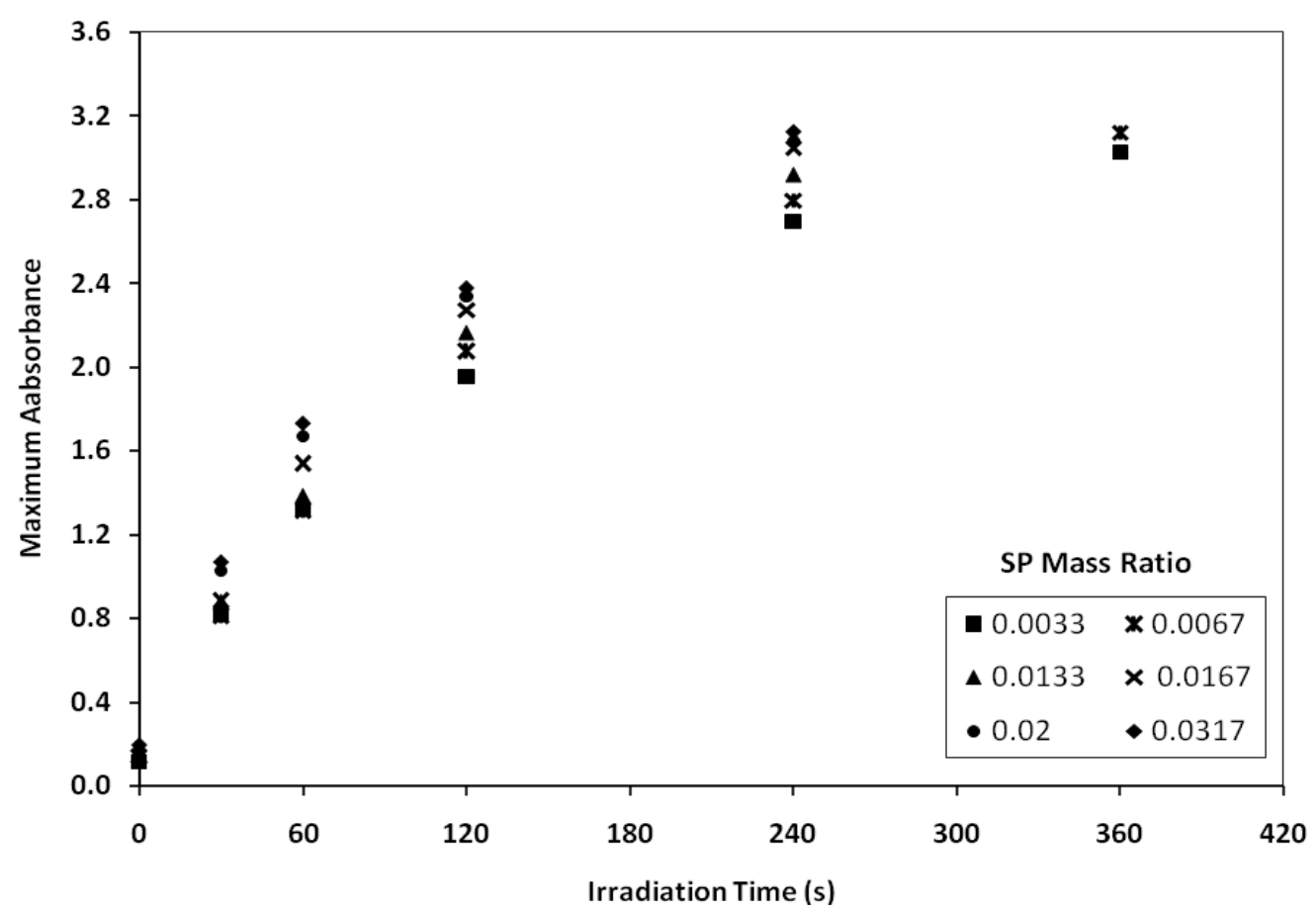

Figure 12: Influence of irradiation time on the maximum absorbance of Tecoflex-EG100A films with different SP concentrations.

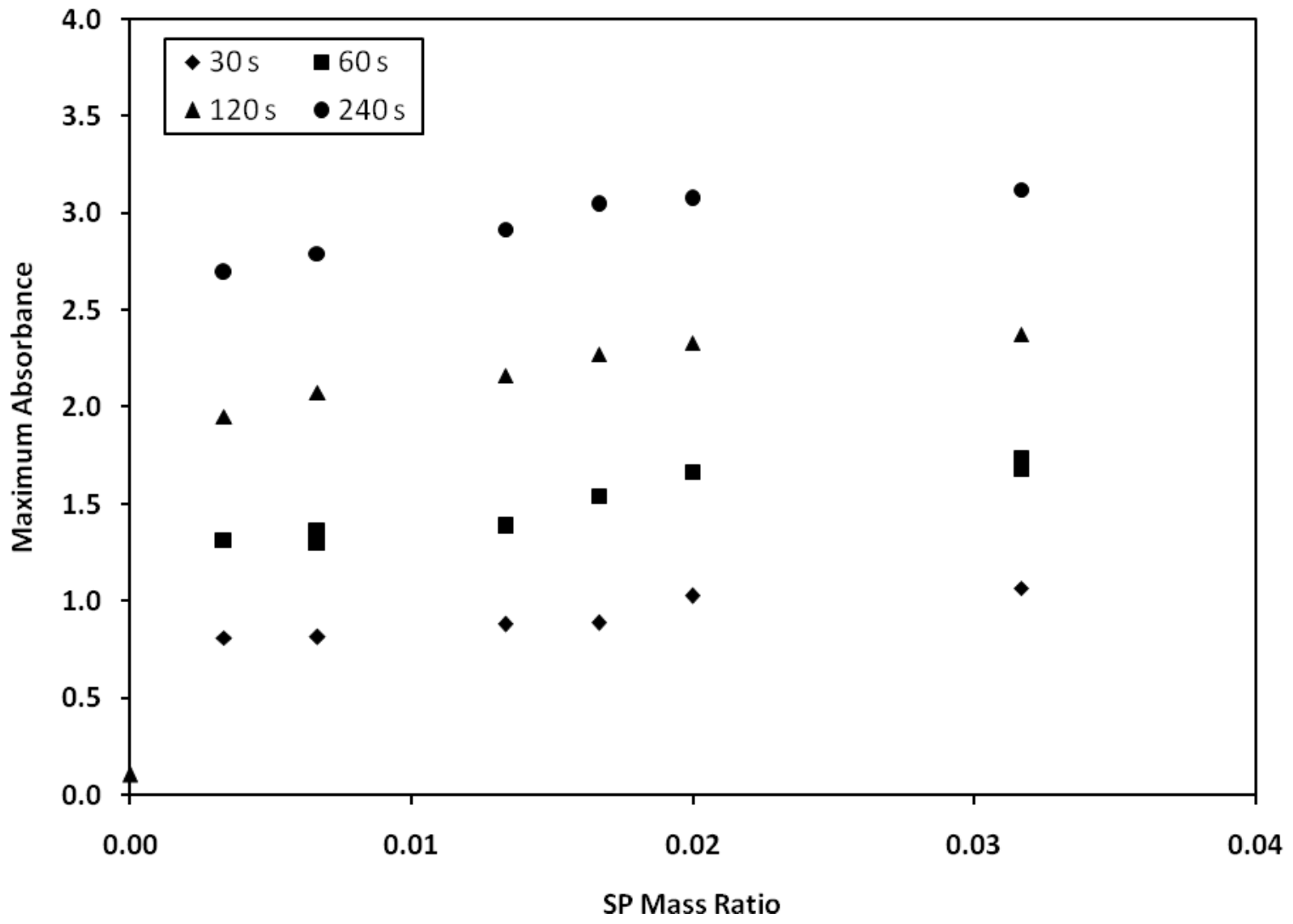

Figure 13: Influence of SP concentration on the maximum absorbance of Tecoflex-EG100A films at different irradiation times. 


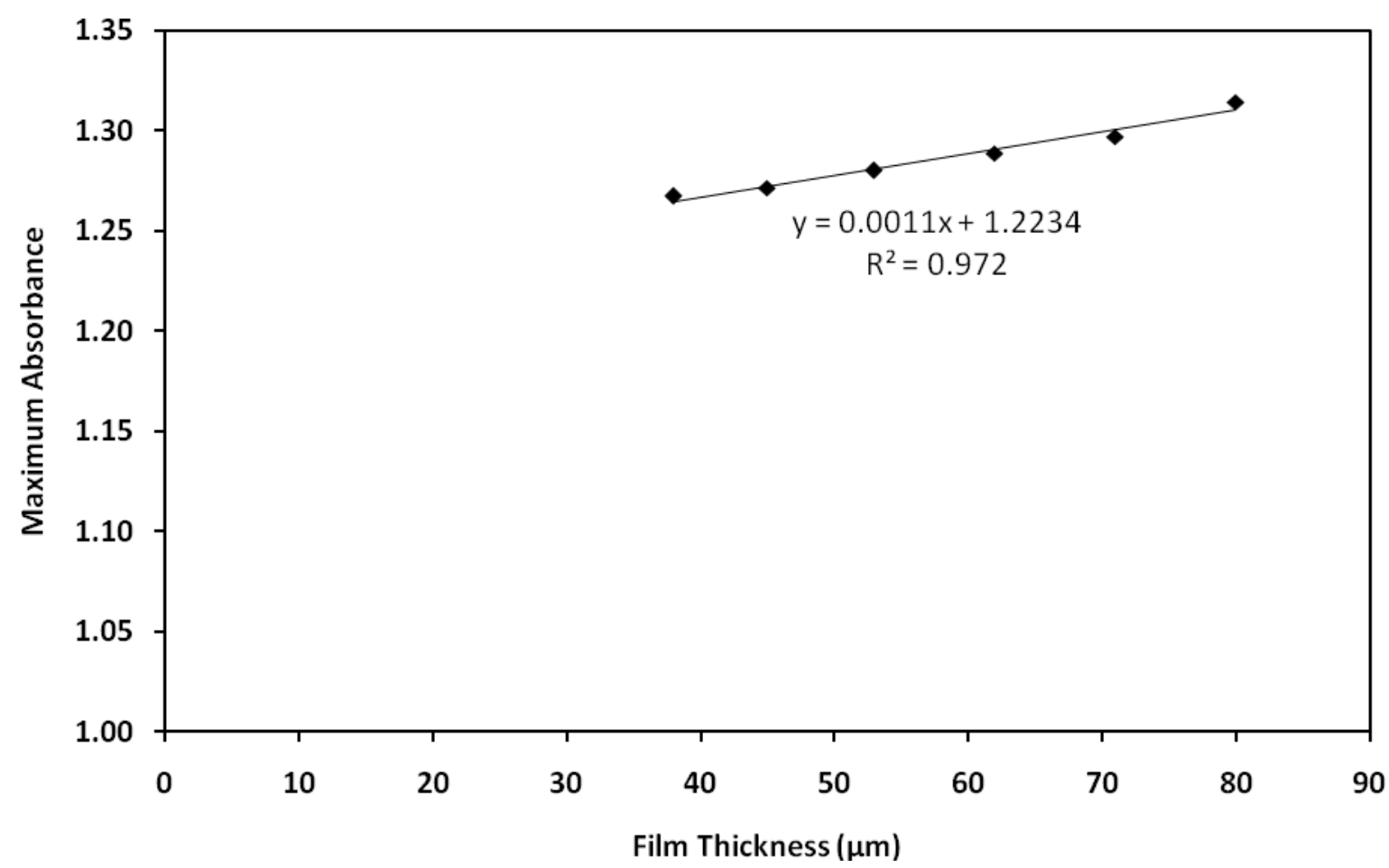

Figure 14: Influence of film thickness on the maximum absorbance after irradiation at $60 \mathrm{~s}$ (Films : Tecoflex-EG100A with SP mass ratio of 0.0067)

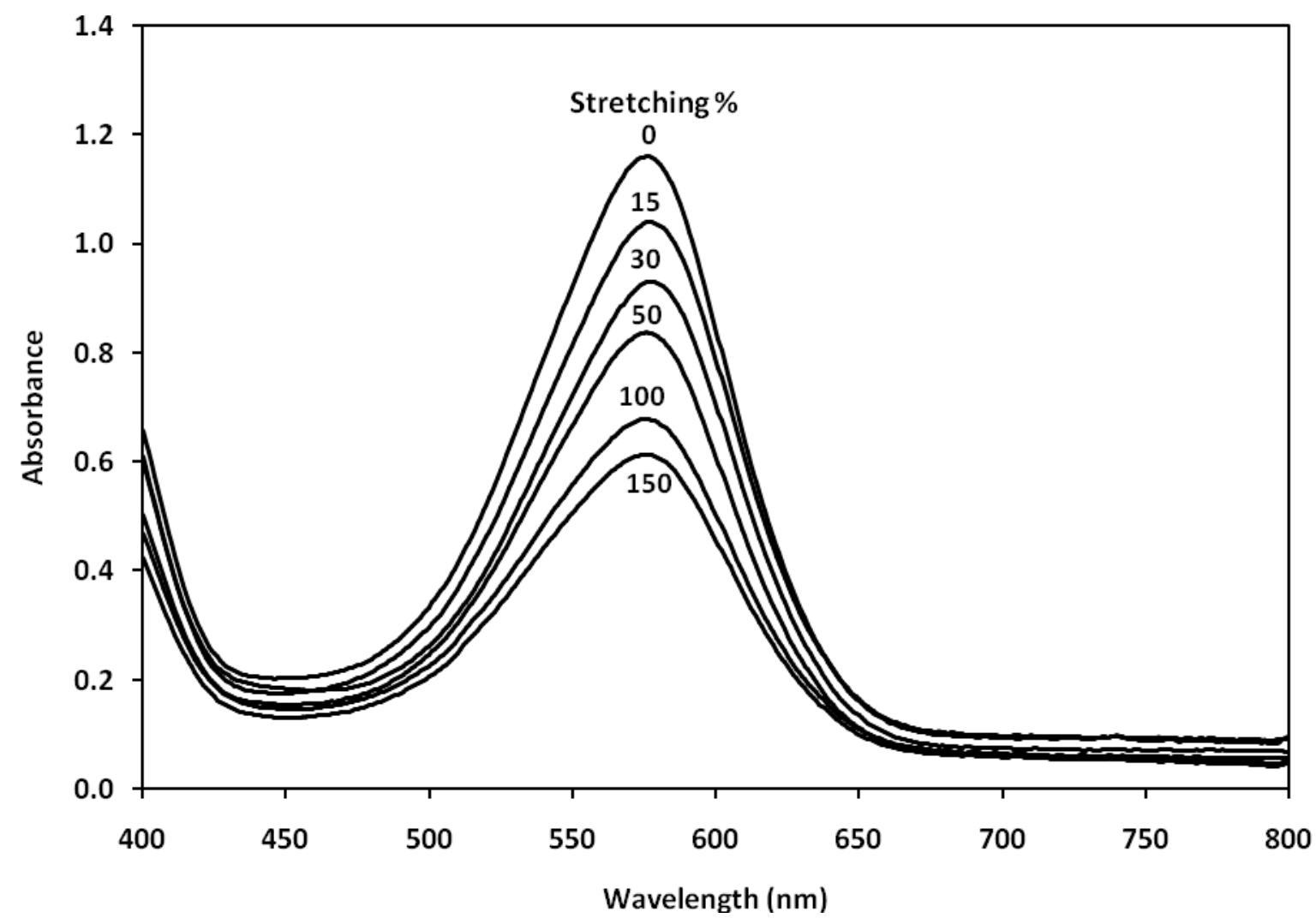

Figure 15: Influence of stretching on the absorbance spectra- First case: Stretching after irradiation. (Films: Tecoflex-EG100A with SP mass fraction of 0.0067) 


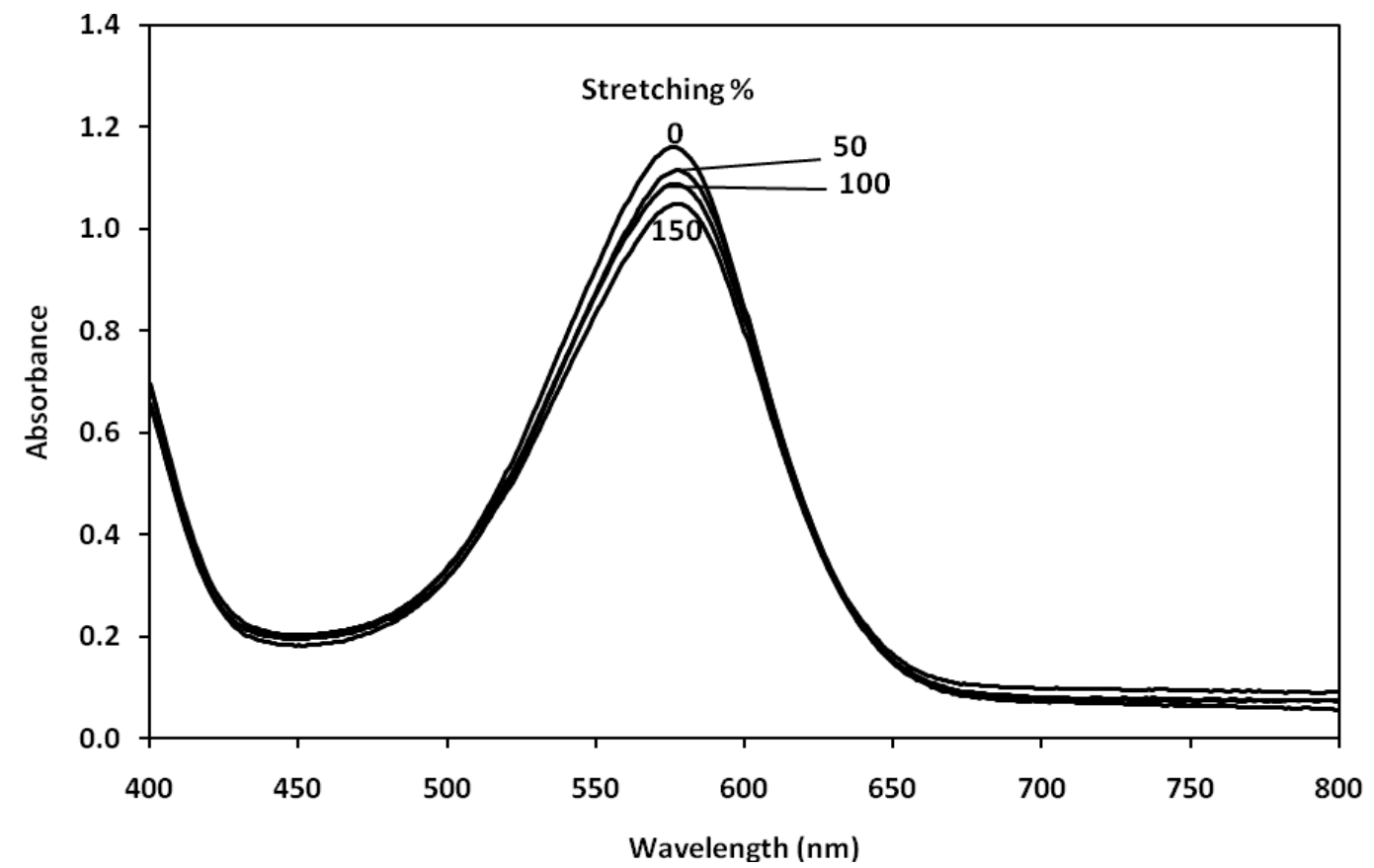

Figure 16: Influence of stretching on the absorbance spectra - Second case: Stretching before irradiation. (Films: Tecoflex-EG100A with SP mass fraction of 0.0067)

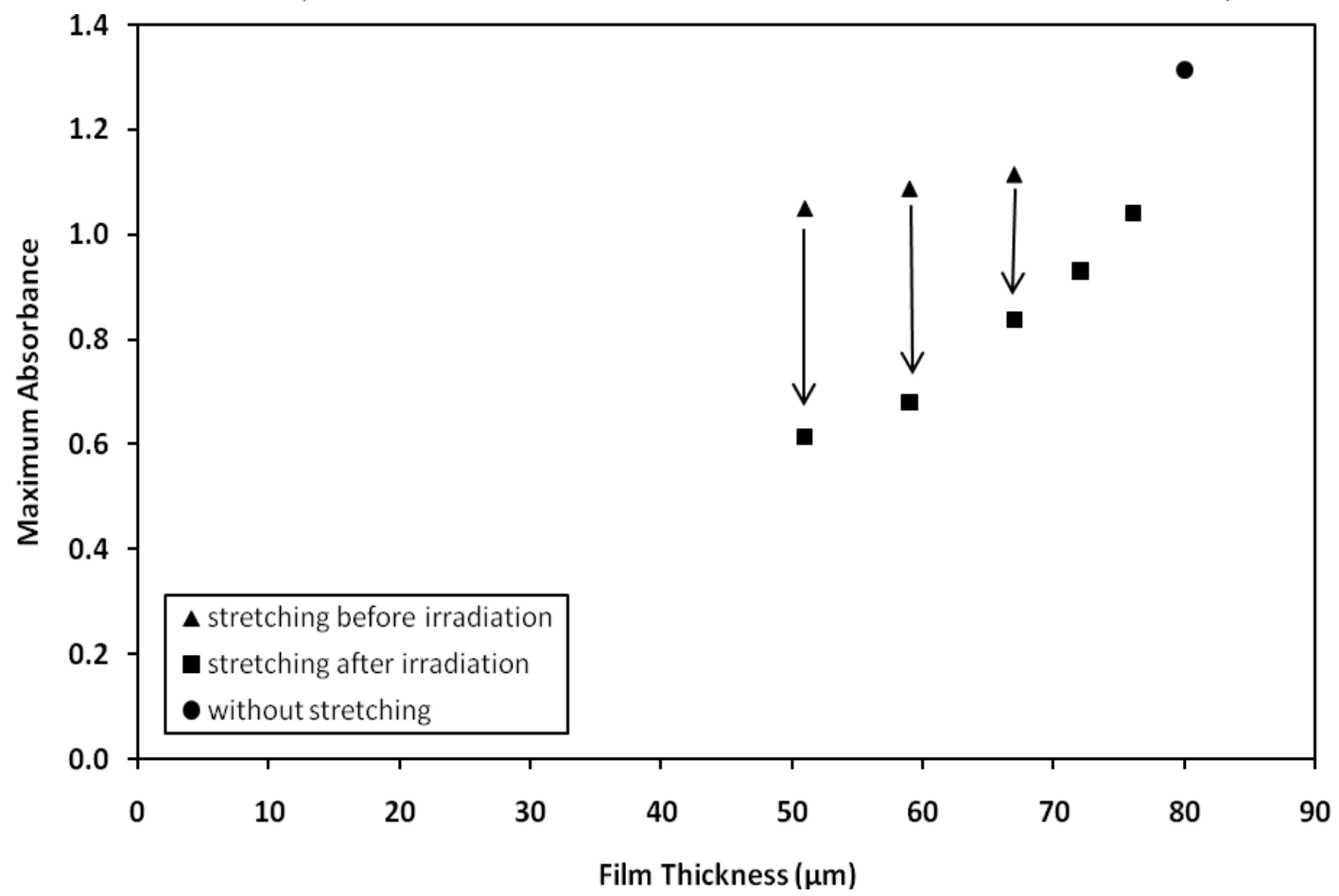

Figure 17: Influence of stretching on the absorbance spectra for stretching after (first case) or before irradiation (second case) as a function of polymer film thickness after stretching. (films :

Tecoflex-EG100A with SP mass fraction of 0.0067) 


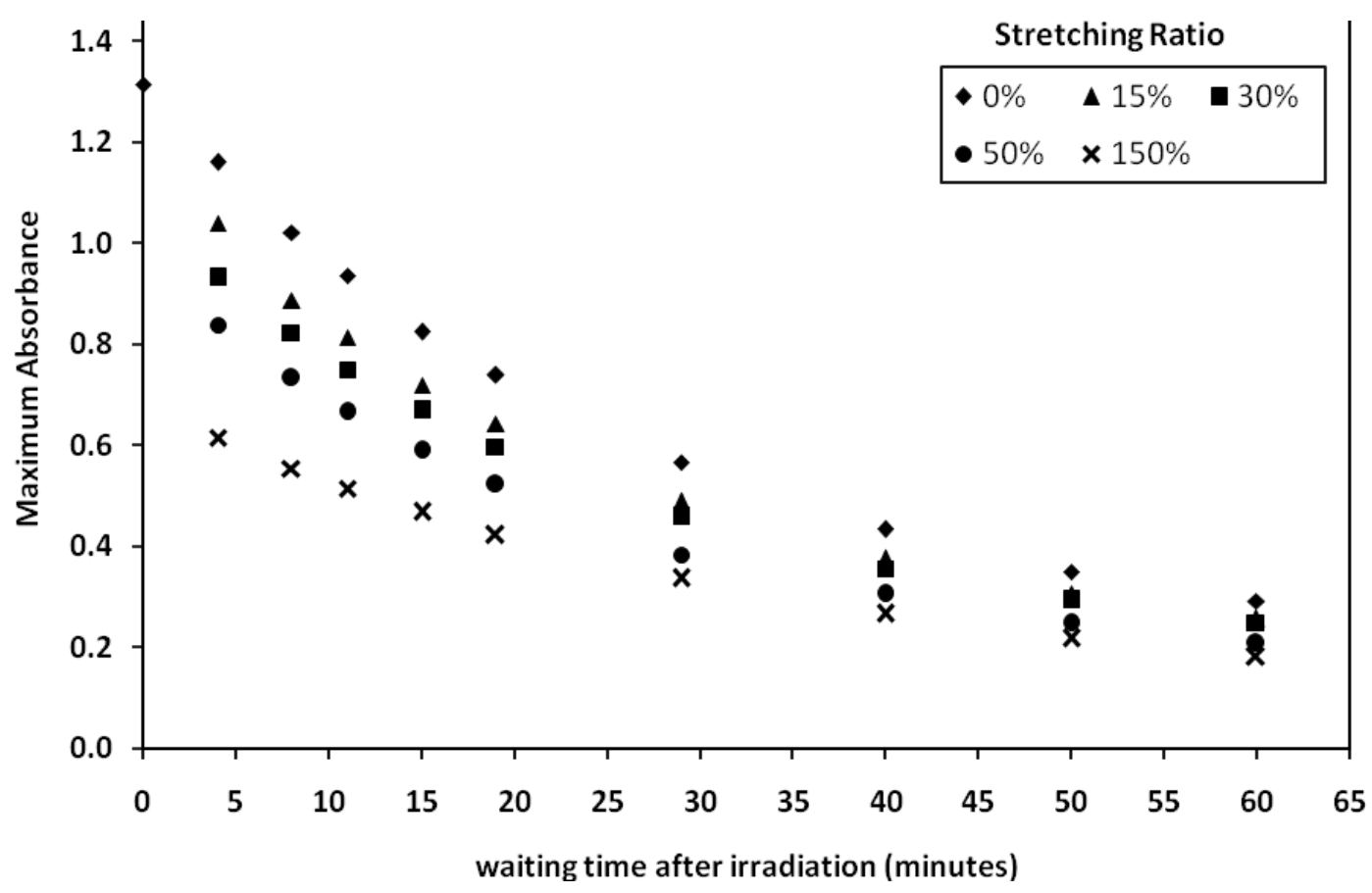

Figure 18: Influence of discoloration time on the maximum absorbance for different stretching ratio - First case: Stretching after irradiation.

(Films: Tecoflex-EG100A with SP mass fraction of 0.0067)

Table 1: Characteristics of the Tecoflex-EG100A polyurethane

\begin{tabular}{|l|l|}
\hline \multicolumn{1}{|c|}{ Type } & \multicolumn{1}{c|}{ Tecoflex } \\
\hline Grade & EG100A \\
\hline Supplier & LUBRIZOL \\
\hline Hardness, Shore A or D & $94 \mathrm{~A}$ \\
\hline Ultimate Tensile Strength, MPa & 56 \\
\hline Ultimate Elongation, \% & 370 \\
\hline $\begin{array}{l}\text { Tensile Modulus } \\
\text { 100\% elongation, MPa }\end{array}$ & 10.9 \\
300\% elongation, MPa & 38.3 \\
\hline $\begin{array}{l}\text { Number average molecular weight, } \overline{\mathrm{M}_{\mathrm{n}}}, \text { g.mol }^{-1} \\
\text { Density, kg/m }{ }^{3}\end{array}$ & 21240 \\
\hline $\begin{array}{l}\text { Glass Transition } \\
\text { Temperature }\left(\mathrm{T}_{\mathrm{g}}\right),{ }^{\circ} \mathrm{C}\end{array}$ & 1090 \\
\hline
\end{tabular}


Military Technical College

Kobry El-Kobbah, Cairo, Egypt

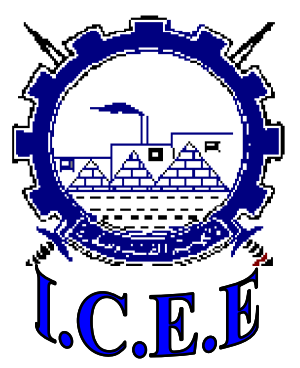

$5^{\text {th }}$ International Conference on

Chemical \& Environmental Engineering 25 - 27 May, 2010. 